Article

\title{
Drought Mitigation Ability Index and Application Based on Balance between Water Supply and Demand
}

\author{
Shaohua Liu ${ }^{1}$, Denghua Yan ${ }^{1, *}$, Jianhua Wang ${ }^{1}$, Baisha Weng ${ }^{1}$, Gang Wang ${ }^{2}$ \\ and Meijian Yang ${ }^{1}$
}

1 State Key Laboratory of Simulation and Regulation of Water Cycle in River Basin, China Institute of Water Resources and Hydropower Research (IWHR), Beijing 100038, China; E-Mails: shliuiwhr@hotmail.com (S.L.); wjh@iwhr.com (J.W.); baishaweng@126.com (B.W.); oymj2082@163.com (M.Y.)

2 Beijing Municipal Research Institute of Environmental Protection, Beijing 100037, China; E-Mail: gangwnan@163.com

* Author to whom correspondence should be addressed; E-Mail: yandh@iwhr.com; Tel.: +86-10-6878-1656; Fax: +86-10-6848-3367.

Academic Editor: Athanasios Loukas

Received: 15 February 2015 / Accepted: 3 April 2015 / Published: 27 April 2015

\begin{abstract}
Drought impacts not only nature, but also the socioeconomic system and results from the imbalance of water supply and demand. It is necessary to estimate the ability of drought mitigation on the basis of water allocation. In this research, the drought mitigation ability index (DMAI) was constructed by the ratio of theoretical water supply and demand obtained from the optimal water allocation. Then, the DMAI was applied to Daqinghe watershed for temporal-spatial validation compared with the agricultural affected areas and the distribution of groundwater overexploitation. In addition, the historical (1961-2010) and future (2020) DMAI in Daqinghe watershed were analyzed. The results show that DMAI can overall represent the temporal-spatial characteristics of the drought mitigation ability. Furthermore, the DMAI of Daqinghe watershed is significantly decreased in the last 50 years, and groundwater resources play a prominent role in drought mitigation. Although the water from the South-to-North Water Transfer Project (SNWTP) can improve DMAI of Daqinghe watershed, the drought risk continues to be serious in the future.
\end{abstract}


Keywords: drought mitigation ability index (DMAI); theoretical water supply and demand; optimal water allocation; temporal-spatial validation; Daqinghe watershed

\section{Introduction}

Droughts are recurrent and world-wide natural hazards, impacting the development of ecosystems, the environment and socio-economic systems [1]. Drought occurrences have been more frequent, and their effects have been aggravated in recent years [2-4]. On the one hand, climate changes have already altered, and will continue to alter, the hydrological cycle, and the hydrological uncertainty has increased significantly [5]. On the other hand, growing urban population, increasing agriculture production and socioeconomic development have contributed to the rise of water demand, especially in China [6-8]. As a result, droughts have affected socioeconomic development and become one of the threats against sustainable development in many countries [9-12].

As a complex and dangerous phenomenon, droughts have attracted the attention of various researchers over the last few decades [7]. A lot of research has been done on drought monitoring [13,14] and drought assessment $[15,16]$. Among this research, various drought indices have been developed to quantify the drought, including multiple drought indices, like the standardized precipitation index (SPI) [17,18], the Palmer drought severity index (PDSI) [19], the surface water supply index (SWSI) [20] and the soil moisture drought index (SMDI) [21]. Meanwhile, due to the complex impacts of drought [22] and regional diversity in the water supply system, there is no index on drought mitigation, which is required and more important to cope with drought disasters. Drought mitigation measures have been classified into three categories: supply-oriented measures, demand-oriented measures and impact-minimization measures [23]. Hence, the drought mitigation ability can be improved by increasing water supply, reducing water demand and optimal water allocation based on the water balance of the supply and demand system. Some studies have demonstrated the effectiveness of the optimal water allocation for drought mitigation [12,24,25]. However, the drought mitigation ability is significantly different among various regions or basins and depends on the local water resource condition, water supply system and socioeconomic status [26-28]. Consequently, drought mitigation is a local and watershed issue, and the drought mitigation ability index (DMAI) should be constructed based on the local condition of water demand and supply [29,30], which is necessary for and meaningful to drought risk management.

In this paper, the Daqinghe watershed, a typical semi-arid basin under great drought stress, is selected as the study area (Section 2.1). Additionally, the materials and the calculation of the DMAI, constructed based on the ratio of theoretical water demand and water supply, are demonstrated in Sections 2.2 and 2.3 , respectively. Then, Section 3 is a case study including the application and validation of the DMAI at temporal-spatial scales in the Daqinghe watershed. Finally, conclusions are given in Section 4. 


\section{Materials and Methods}

\subsection{Study Area}

The Daqinghe watershed is located in the middle of the Haihe River Basin with the most serious water stress in China. The Daqinghe River originates in Taihang Mountain, and the watershed with a sector-shape is surrounded by Taihang Mountain in the west, Bohai Sea in the east, Yongdinghe River in the north and Ziyahe River in the south. The river basin area is over $40,000 \mathrm{~km}^{2}$, of which mountain and hillside area (MHA) account for $43 \%$ and plain areas for $57 \%$, and is divided into two partitions by Baiyangdian Lake (the eastern and western Baiyangdian plain (EBP and WBP, respectively)). Based on the joint distribution of the natural river system and the administrative division (Baoding city, Shijiazhuang city, Cangzhou city, Langfang city, Hengshui city, Zhangjiakou city, Tianjin city, Beijing city and Shanxi province), the Daqinghe watershed was divided into 13 basic units (Figure 1). According to the requirement of water allocation, the water supply network was constructed (Figure 2) by abstracting and conceptualizing the hydraulic relation between basic units, river channel system and reservoirs.

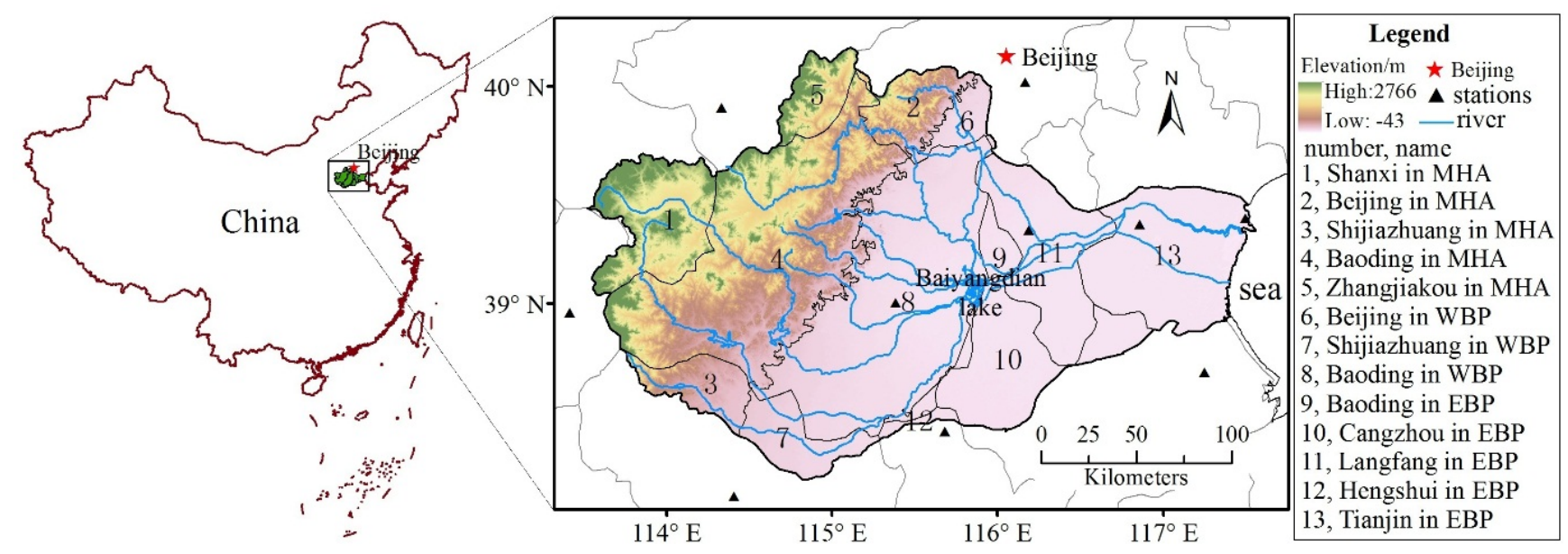

Figure 1. Location of the basic units in the Daqinghe watershed. MHA, mountain and hillside area; WBP, western Baiyangdian plain; EBP, eastern Baiyangdian plain.

\subsection{Materials}

Two datasets of water resource quantity and water demand on a monthly scale during 1961-2010 in the Daqinghe watershed were used in the research. According to the principles of equality and sustainability, the water resources were optimally allocated with the goal of minimizing the total water shortage, and the monthly balance between water supply and demand were calculated by the general algebraic modeling system (GAMS), a mathematical programming and optimization model system. The dataset of water resource quantity was acquired from the National Comprehensive Planning of Water Resources (1961-2000) and the Water Resources Bulletin in Haihe River Basin (2000-2010). The domestic, industrial and ecological water demand data in the dataset of water demand were acquired from the Water Resources Bulletin of the base year (2010); the agricultural water demand was calculated by deviation between theoretical agricultural water demand and effective precipitation during the crop 
growth period. Additionally, daily meteorological data, such as precipitation, evaporation, humidity, wind speed, sunshine hours and vapor pressure, of 10 meteorological stations (Figure 1 and Table 1) within and around the watershed were gained from China Meteorological Data Sharing Service System during 1961-2010 [31].

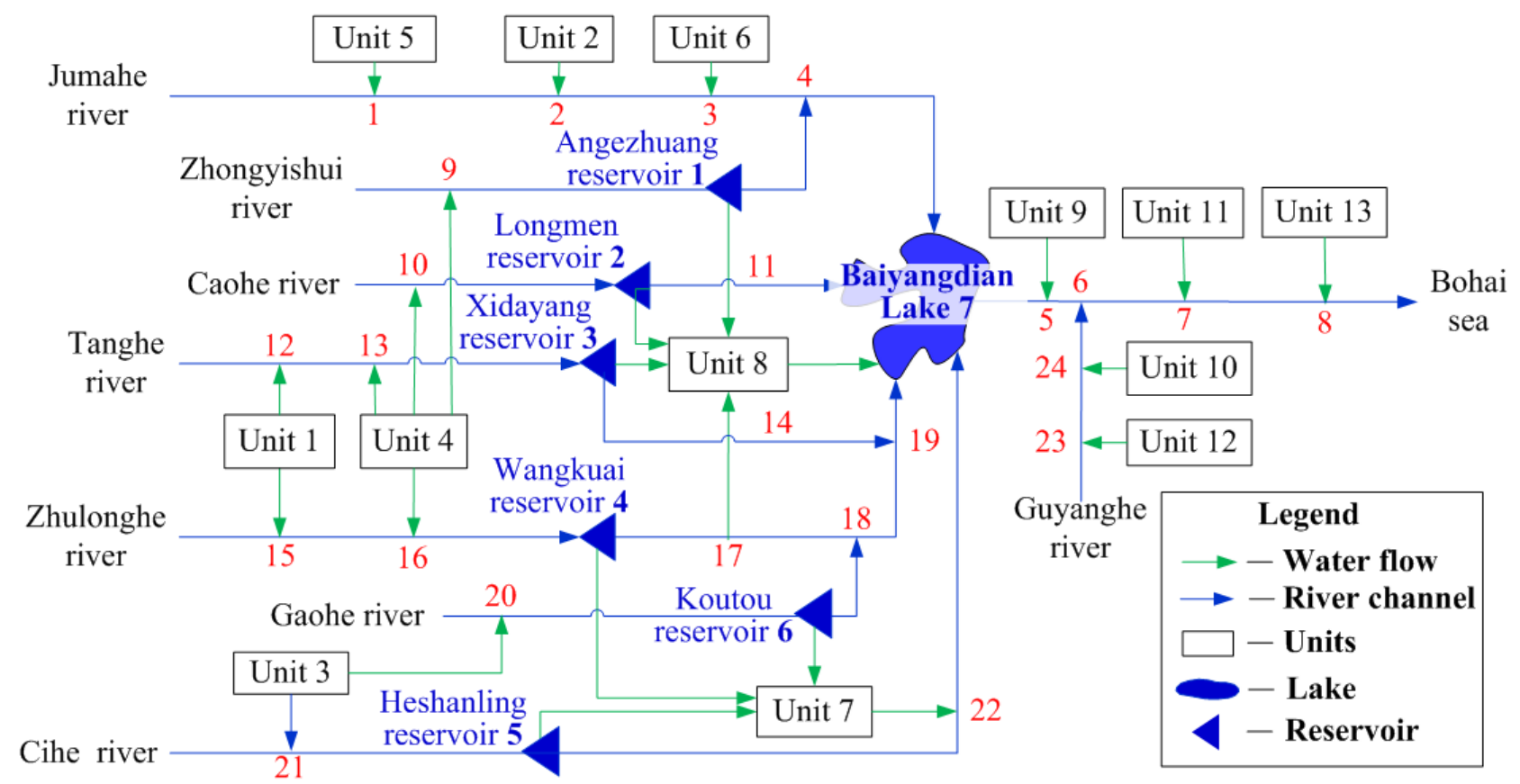

Figure 2. Water supply network in the Daqinghe watershed. The red and blue digits are the number of river channels and reservoirs, respectively. With the impact of water flows, the river channel has been divided into sections, and these can be used as catchments in the water allocation model. Furthermore, all of the units have local ground water supply in the Daqinghe watershed, which means the number of ground water supply can be equal to the number of units. Thus, the number of ground water supply is not depicted to simplify the network.

Table 1. Information of the meteorological stations within and around the watershed.

\begin{tabular}{ccccccc}
\hline Stations & Name & Number & Longitude $^{\circ}$ & Latitude $^{\circ}$ & Elevation/m & Period \\
\hline 1 & Beijing & 54511 & 116.5 & 39.8 & 31.3 & $1951-2010$ \\
2 & Wutaishan & 53588 & 113.5 & 39.0 & 2208.3 & $1951-2010$ \\
3 & Shijiazhuang & 53698 & 114.4 & 38.0 & 81.0 & $1955-2010$ \\
4 & Yuxian & 53593 & 114.6 & 39.8 & 909.5 & $1954-2010$ \\
5 & Bazhou & 54518 & 116.4 & 39.1 & 9.0 & $1957-2010$ \\
6 & Tianjin & 54527 & 117.1 & 39.1 & 2.5 & $1954-2010$ \\
7 & Baoding & 54602 & 115.5 & 38.9 & 17.2 & $1955-2010$ \\
8 & Raoyang & 54606 & 115.7 & 38.2 & 19.0 & $1957-2010$ \\
9 & Tanggu & 54623 & 117.7 & 39.1 & 4.8 & $1954-2010$ \\
10 & Huanghua & 54624 & 117.4 & 38.4 & 6.6 & $1960-2010$ \\
\hline
\end{tabular}




\subsection{Methods}

Drought mitigation ability means to prohibit drought occurrence or to reduce drought impacts through reducing water demand, increasing water resources or optimal water allocation in regions or watersheds. However, total water demand consists of domestic demand, productive demand (industry and agriculture) and ecological demand; it is always difficult and infeasible to reduce water demand. On the other hand, the water resources mainly depend on precipitation, which is uncertain and uncontrollable. Therefore, the optimal water allocation is usually the effective method for drought mitigation. Consequently, the DMAI, as an integrated index to estimate the regional drought mitigation ability, is defined by the theoretical ratio of water supply and demand obtained from the optimal water allocation, and the formula of DMAI can be constructed as follows:

$$
D M A I_{t}=\frac{W_{\text {supply }, t}}{W_{\text {demand }, t}}
$$

where $D M A I_{t}$ is the drought mitigation ability in the period $t ; W_{\text {supply,t }}$ is the theoretical water supply obtained from optimal water allocation in the period $t ; W_{\text {demand, } t}$ is the total theoretical water demand in the period $t$, including domestic water demand, productive water demand and ecological water demand, and it is more than the actual water demand. According to the formula, the $D M A I_{t}$, ranging from 0 to 1 , means maximizing the water supply by optimal water allocation, which is closely related to water supply engineering, the water resource situation and integrated water resource management. Accordingly, the regional DMAI is not a constant and varies under the different water resource situations (flood, normal, or drought year) and the water supply system.

\subsubsection{Calculation of Water Demand}

Regional water demand consists of four main types: domestic water demand, industry water demand, theoretical agricultural water demand and ecological water demand. In the base year of 2010, the water shortages were mainly caused by agricultural water demand, which accounts for about $80 \%$ of the total water demand. Consequently, the domestic water demand, industry water demand and ecological water demand only account for $20 \%$ and were acquired from the base year in this study. Accordingly, the agricultural water demand changes significantly under different water resource situations (flood, normal, or drought year), and the inner-annual water supply-demand processes are highly influenced by runoff processes. Therefore, the agricultural water demand was calculated as the deviation between the theoretical agricultural water demand and effective precipitation during the crop growth period, as:

$$
I_{s, m}=\sum_{n=1}^{N} E T_{c, n}-\sum_{n=1}^{N} P_{e, n}
$$

where $N$ is the number of crop growth days in the $m$-th month; $I_{s, m}$ is the total supplementary water in irrigation in the $m$-th month, mm/month; $E T_{c, n}$ is the theoretical crop water demand in the $n$-th day, $\mathrm{mm}$ /day. The method recommended by the Soil Conservation Board of the United States Department of Agriculture is adopted in this article to calculate the effective precipitation, as Formula (3) [32,33], where $P$ is the measured daily precipitation, $\mathrm{mm} / \mathrm{d}$. 


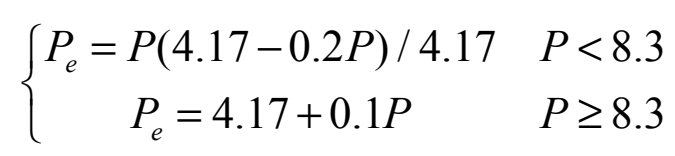

Additionally, crop water demand is calculated by the FAO Penman-Monteith equation, as follows:

$$
\begin{gathered}
E T_{c}=K_{c} \cdot E T_{0} \\
E T_{0}=\frac{0.408 \Delta\left(R_{n}-\mathrm{G}\right)+\gamma \frac{900}{T+273} U_{2}\left(\mathrm{e}_{\mathrm{a}}-\mathrm{e}_{\mathrm{d}}\right)}{\Delta+\gamma\left(1+0.34 U_{2}\right)}
\end{gathered}
$$

where $E T_{c}$ is the theoretical water demand of crop, $\mathrm{mm} / \mathrm{d} ; K_{c}$ is the crop coefficient; $E T_{0}$ is the reference vegetation evapotranspiration, $\mathrm{mm} / \mathrm{d}$. Assume the vegetation height as $0.12 \mathrm{~m}$, the canopy resistance as $70 \mathrm{~s} / \mathrm{m}$ and the ground surface reflectivity as 0.23 when calculating $E T_{0} ; R_{n}$ is the net radiation at the crop surface, $\mathrm{MJ} / \mathrm{m}^{2} \cdot \mathrm{d} ; \mathrm{G}$ is the soil heat flux density, $\mathrm{MJ} / \mathrm{m}^{2} \cdot \mathrm{d} ; T$ is the mean daily air temperature at $2 \mathrm{~m}$ height, ${ }^{\circ} \mathrm{C} ; U_{2}$ is wind speed at $2 \mathrm{~m}$ height, $\mathrm{m} / \mathrm{s} ; \mathrm{e}_{\mathrm{d}}$ is the saturation vapor pressure, $\mathrm{kPa} ; \mathrm{e}_{\mathrm{a}}$ is the actual measured vapor pressure, $\mathrm{kPa} ; \Delta$ is the slope vapor pressure curve, $\mathrm{kPa} /{ }^{\circ} \mathrm{C} ; \gamma$ is the psychrometric constant.

Finally, the regional theoretical agricultural water demand (TAWD) can be acquired from the multiplication of regional crop water demand and farmland area, as:

$$
I_{w, m}=I_{s, m} \times A_{a g r, m}
$$

where $I_{w, m}$ is the TAWD in the $m$-th month, $1000 \mathrm{~m}^{3} /$ month; $I_{s, m}$ is the total supplementary water in irrigation in the $m$-th month, mm/month; $A_{a g r, m}$ is the regional effective irrigation area, $\mathrm{km}^{2}$. According to the calculation method of TAWD, it can be seen that the TAWD is absolutely more than actual agricultural water demand, since the $E T_{c}$ is relatively more than actual vegetation evapotranspiration. Nevertheless, the $E T_{c}$ can also manifest the potential water demand of crop under the ideal soil moisture condition. In addition, the TAWD can represent the potential agricultural water demand with the adequate water supply scenario. Then, with the above material input and calculations of water demand, the monthly water demand within the Daqinghe watershed from 1961 to 2010 was obtained. Moreover, the average annual ecological, domestic, industry and agricultural water demands during 1961-2010 are shown in Table 2.

Table 2. Average annual ecological, domestic, industry and agricultural water demand within the Daqinghe watershed. (Unit: 10,000 $\mathrm{m}^{3}$ ).

\begin{tabular}{ccccc}
\hline Units & $\begin{array}{c}\text { Ecological } \\
\text { Water Demand }\end{array}$ & $\begin{array}{c}\text { Domestic } \\
\text { Water Demand }\end{array}$ & $\begin{array}{c}\text { Industry } \\
\text { Water Demand }\end{array}$ & $\begin{array}{c}\text { Agricultural } \\
\text { Water Demand }\end{array}$ \\
\hline Unit 1 & 34.12 & 622.72 & 358.28 & 4197.40 \\
Unit 2 & 29.76 & 543.05 & 312.44 & 9503.21 \\
Unit 3 & 238.28 & 4348.63 & 2501.95 & $32,117.37$ \\
Unit 4 & 27.19 & 496.28 & 285.53 & 1596.28 \\
Unit 5 & 402.14 & 2380.93 & 1506.43 & $10,750.44$ \\
\hline
\end{tabular}


Table 2. Cont.

\begin{tabular}{ccccc}
\hline Units & $\begin{array}{c}\text { Ecological } \\
\text { Water Demand }\end{array}$ & $\begin{array}{c}\text { Domestic } \\
\text { Water Demand }\end{array}$ & $\begin{array}{c}\text { Industry } \\
\text { Water Demand }\end{array}$ & $\begin{array}{c}\text { Agricultural } \\
\text { Water Demand }\end{array}$ \\
\hline Unit 6 & 778.66 & 4610.16 & 2916.88 & $22,614.60$ \\
Unit 7 & 5119.20 & $30,308.91$ & $19,176.68$ & $160,680.06$ \\
Unit 8 & 70.65 & 1289.32 & 741.80 & 8120.21 \\
Unit 9 & 775.44 & 3673.83 & 3247.97 & $15,162.34$ \\
Unit 10 & 3259.42 & $15,442.15$ & $13,652.15$ & $64,608.18$ \\
Unit 11 & 3422.81 & $16,216.27$ & $14,336.53$ & $67,564.54$ \\
Unit 12 & 181.60 & 860.37 & 760.64 & 3369.58 \\
Unit 13 & 4560.73 & $21,607.38$ & $19,102.72$ & $57,188.71$ \\
\hline
\end{tabular}

\subsubsection{Calculation of Water Supply}

Regional theoretical water supply is the water supply ability to satisfy the water demand of every unit through optimal water allocation model. Based on the water supply network, the linear programming model of GAMS was applied to obtain the theoretical water supply in the Daqinghe watershed. The constraints consist of the water balance of units (Equation (7)), water balance of reservoirs (Equations (8) and (9)) and water balance of river channels (Equations (10) and (11)), and the objective function is Equation (12).

$$
\begin{gathered}
\text { Demand }_{i, t}-\alpha_{i} \text { Supply }_{i, t}^{g}-\beta_{i} \text { Supply }_{i, t}^{s}-\eta_{i} \text { Supply }_{i, t}^{R_{k}}-\lambda_{i} \text { Supply }_{i, t}^{r_{j}}=\text { Shortage }_{i, t} \\
S_{j, t-1}+\text { Qin }_{j, t}-\sum_{i=1}^{13} \text { Supply }_{i, t}^{r_{j}}-\text { Qout }_{j, t}-L_{j, t}^{S}=S_{j, t} \\
S_{j, \text { min }} \leq S_{j, t} \leq S_{j, \max } \\
R_{k, t-1}+\sum_{i=1}^{13} \operatorname{surface}_{i, t}^{k}-\sum_{i=1}^{13} \operatorname{Supply}_{i, t}^{s}+\sum_{j=1}^{7} \operatorname{Rin}_{k, t}-\sum_{i=1}^{13} \operatorname{Supply}_{i, t}^{R_{k}}-\sum_{j=1}^{7} \text { Rout }_{k, t}-L_{k, t}^{R}=R_{k, t} \\
R_{k, \min } \leq R_{k, t} \leq R_{k, \max } \\
\text { obj }=\min \left(\sum_{t=1}^{n} \sum_{i=1}^{13} \omega_{i} \text { Shortage }_{i, t}\right)
\end{gathered}
$$

where $t$ is the monthly time step; $n$ is the termination time; $i$ is the number of units; $j$ is the number of reservoirs (Baiyangdian Lake was considered as a reservoir); $k$ is the number of river channels; Demand $_{i, t}$ is the total water demand (consisting of domestic water demand, agricultural water demand, industry water demand and ecological water demand); Supply $y_{i, t}^{g}$ is the local ground water resources to supply the $i$-th unit; Supply $y_{i, t}^{s}$ is local surface water resources derived from the local precipitation to supply the $i$-th unit; Supply $y_{i, t}^{R_{k}}$ is the remaining water resources of the upstream river channel, derived from the precipitation of upstream units, to supply the $i$-th unit after the water supply of upstream units; Supply $y_{i, t}^{r_{j}}$ is the $r_{i}$-th reservoir water supply to the $i$-th unit; Shortage $e_{i, t}$ is the $i$-th unit water shortage; $\alpha_{i}, \beta_{i}, \eta_{i}$ and $\lambda_{i}$ are the water use efficiency of ground water, local surface water, river channel water and reservoir water, accordingly; $S_{j, t}$ is the effective water storage of the $j$-th reservoir; $S_{j, \min }$ and $S_{j, \max }$ 
are the minimum and maximum reservoir storage, respectively; $Q_{j, t}$ is the inflow into the $j$-th reservoir; Qout ${ }_{j, t}$ is the water release to the downstream river channel from the reservoir; $L_{j, t}^{S}$ is the water loss in the reservoir, including evaporation and infiltration losses. $R_{k, t}$ is the effective water storage of the river channel; $R_{k, \min }$ and $R_{k, \max }$ are the minimum and maximum water storage in the river channel for ecological water demand and flood protection, respectively; $\operatorname{Rin}_{k, t}$ and Rout $_{k, t}$ are the inflow and outflow of the $k$-th river channel, accordingly; $L_{k, t}^{R}$ is the water loss in the channel; $\omega_{i}$, determining the priority of units water supply, is the weight of units of water shortage, severally, the higher weight meaning a prior water supply opportunity. Additionally, all of the weights are equivalent to 1, which implies the justification of the water supply between units in this study, and all the variables in the equations above are non-negative.

\section{Results and Discussion}

\subsection{Index Validation}

\subsubsection{Temporal Scale}

Baoding is located in the central part of the Daqinghe watershed and accounts for more than half of the watershed. Research [34,35] shows that there is an exponential relationship between agricultural drought-affected areas (ADAA) and the magnitude of drought. Based on the ADAA over the years from the Economic Statistical Yearbook of Baoding (1995-2011), the ADAA was processed by logarithmic transformation (inverse to exponential transformation) to acquire the logarithmic indexes of agriculture drought-affected areas (LIADAA), which was compared with the agricultural DMAI (aDMAI) of Baoding (Figure 3). The result shows that the LIADAA basically agrees with the reverse trends of aDMAI over the years in Baoding, with a correlation coefficient of 0.67 . Additionally, due to the differences of annual hydrological processes, planting structure, and so forth, the LIADAA are significantly inconsistent with aDMAI in the years of 1995 and 1996. Nevertheless, the aDMAI can overall reveal the regional response to agricultural drought and represent the ability to mitigate the drought impact effectively.

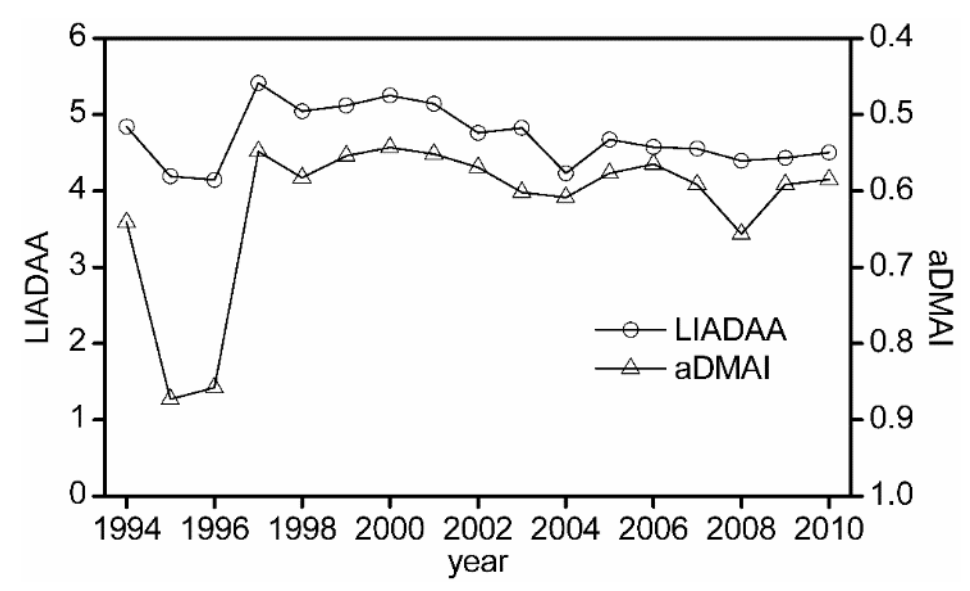

Figure 3. Comparison of logarithmic indexes of agriculture drought-affected areas (LIADAA) and agricultural drought mitigation ability index (aDMAI) in Baoding City. 


\subsubsection{Spatial Scale}

Groundwater resources are the primary sources for water resource exploitation and utilization under serious water resource stress in the Daqinghe watershed. The drought mitigation mainly depends on pumping groundwater particularly in the place with low drought mitigation ability. Therefore, according to the average annual groundwater overexploitation data of every city from 2001 to 2010, the rationality of the spatial distribution of the drought mitigation ability was validated by the comparison of the average annual DMAI distribution (Figure 4a) and the groundwater overexploitation distribution. The result manifests that the distribution of drought mitigation ability is to some extent consistent with the distribution of groundwater overexploitation (Figure 4b), and the units with low drought mitigation ability in plain areas are also the severest groundwater overexploitation areas.
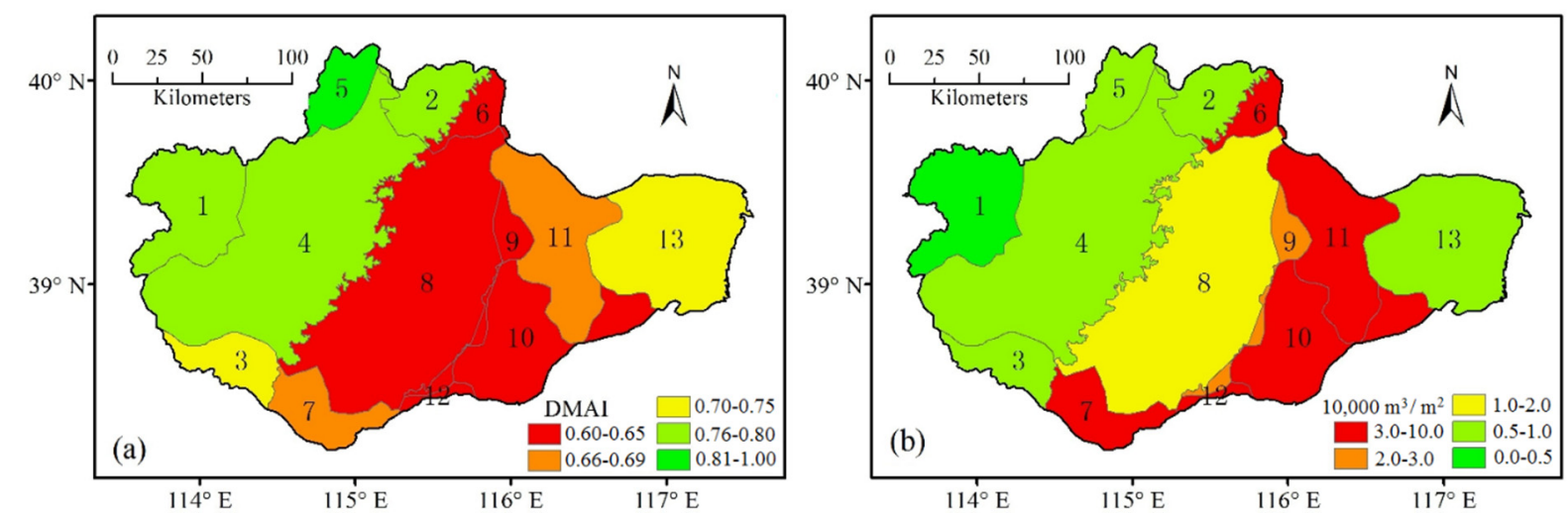

Figure 4. Distribution of the (a) drought mitigation ability index (DMAI) and (b) groundwater overexploitation.

The temporal-spatial validation of the drought index is a hot and tough issue, due to the fuzzy onset and end characteristics [36] and complex impacts of drought [22]. Therefore, spatial validation is infrequent and unquantifiable in the current research. According to the above result, although DMAI had not been perfectly validated, it can overall represent the regional ability for drought mitigation in the temporal-spatial scales within the Daqinghe watershed, which means that the DMAI is obviously beneficial to the drought risk management at the regional/basin scale.

\subsection{Evolution of the Drought Mitigation Ability Index (DMAI) Characteristics in the Daqinghe Watershed}

\subsubsection{Annual Evolution Characteristic of the Drought Mitigation Ability Index (DMAI)}

The trend of the DMAI for the overall Daqinghe watershed was calculated during 1961-2010 (Figure 5a). The result reveals that there is a decreasing trend of the DMAI over the last 50 years. Then, the contribution rate of groundwater and surface water to the DMAI were computed from the ratios of groundwater and surface water supply to the total water supply in DMAI (Figure 5b,c). As a result, the sum of the contribution rates of groundwater and surface water equal one. The contribution rate of groundwater to the DMAI shows an increasing trend, while it is opposite for the surface water. The groundwater contribution rate was significantly high, even more than $90 \%$, particularly in typical drought years (such as 1965, 1968, 1972, etc.). This indicates that the decrease of the DMAI will 
aggravate the drought risk of the Daqinghe watershed in the future, and groundwater overexploitation, which has caused a series of environmental-ecological problems [37], will be more serious.
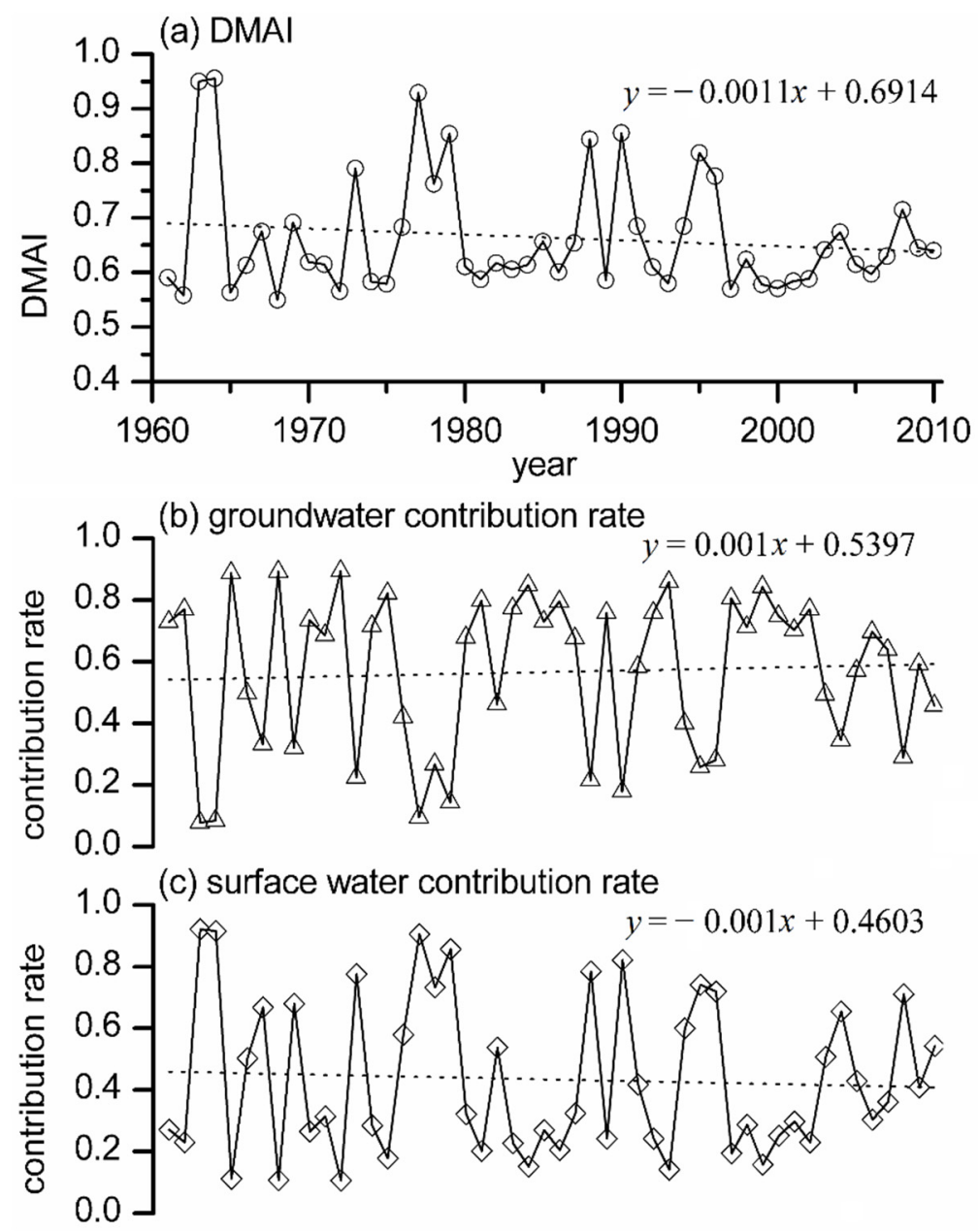

Figure 5. Trends of annual (a) drought mitigation ability index (DMAI); (b) groundwater and (c) surface water contribution rate in the Daqinghe watershed.

\subsubsection{Evolution Characteristics of the Drought Mitigation Ability Index (DMAI) in Typical} Drought Years

In order to better understand the DMAI characteristics in typical drought years, the exceedance probability of $X$ exceeding or equaling a specific value $x(\mathrm{~m})$ is defined as:

$$
P(X \geq x(\mathrm{~m}))=\frac{m}{n+1}
$$

where $X$ is the annual water resources in the Daqinghe watershed, a random variable during 1961-2010; $x(\mathrm{~m})$ is the $m$-th largest observation value of $X$; and $\mathrm{n}$ is the total number of observations; a higher exceedance probability means a more serious drought year. Additionally, the exceedance probabilities of annual water resources were obtained based on historical data from 1961 to 2010. According to the exceedance probability of annual water resources, annual DMAI of each unit had been analyzed in typical drought years (1986, 1997 and 1965 are the 75\%, 90\% and 95\% exceedance probabilities of annual water resource quantity, respectively) (Figure 6a). The result shows that the DMAI of 
Units 6-12 in plain areas is somewhat lower than the DMAI of Units 1-5 in MHA, except for Unit 13, which is located in Tianjin with higher precipitation and next to the Bohai Sea. In addition, the DMAI deviation between $75 \%, 90 \%$ and $95 \%$ exceedance probabilities and average annual water resources were acquired (Figure 6b). The result displays that the DMAI of Units 1-8 in WBP and MHA decrease more dramatically in drought years, especially in Unit 7, with the most water demand (Table 2). The reason is that the units in EBP can use the water from the upstream to improve their DMAI. However, the DMAI of units in MHA and WBP mostly rely on the local water resources. Consequently, the DMAI changes are accompanied with the changes of water resources in the MHA and WBP areas.

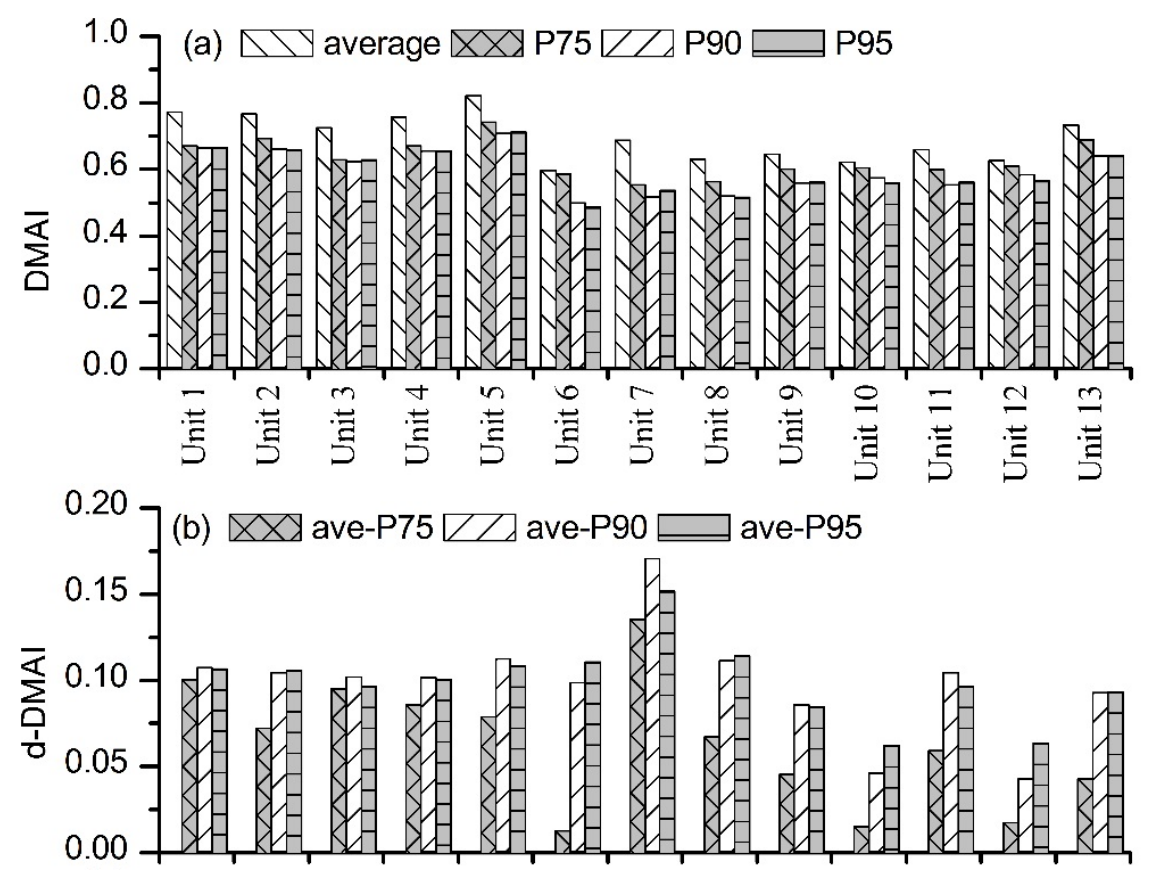

Figure 6. DMAI of units in typical drought years: (a) "average" represents the average annual drought mitigation ability index (DMAI); P75, P90 and P95 represent the 75\%, 90\% and $95 \%$ exceedance probabilities of annual water resources, respectively; (b) ave-P75, ave-P90 and ave-P95 represent the DMAI deviation between 75\%, 90\%, 95\% exceedance probabilities and average annual value.

\subsubsection{Inner-Annual Evolution Characteristics of the Drought Mitigation Ability Index (DMAI)}

Average monthly DMAI over the years of 1961-2010 is illustrated in Figure 7. It shows that the months with low DMAI are from March to June, August and September accordingly. Unfortunately, the primary crop types in the Daqinghe watershed are winter wheat and summer maize. Their growth periods are from March to June and from August to October, separately, which almost coincides with the low DMAI months. On the one hand, the high agricultural water demand is the reason for the low DMAI in the growing season. On the other hand, the agricultural drought will still be a big challenge for drought mitigation in the Daqinghe watershed, which is consistent with the severe agricultural drought problems in reality. 


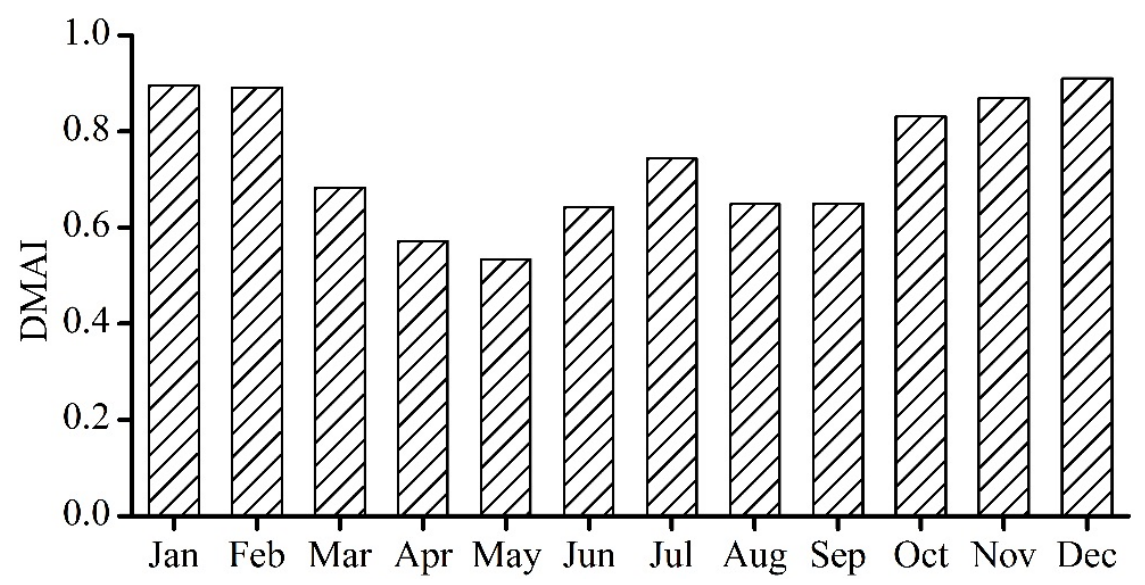

Figure 7. Distribution of monthly drought mitigation ability index (DMAI) within the Daqinghe watershed.

\subsection{Drought Mitigation Ability Index (DMAI) Changes in the 2020}

\subsubsection{Water Resources Decrease Impact on Drought Mitigation Ability Index (DMAI)}

According to the trends of the water resources and demand in the last 50 years (Figure 8), water demand shows a slight decreasing trend, and water resources (surface water and groundwater) have a significant decreasing trend attributed to climate change and local human activities, which is the prominent reason for the DMAI decrease. Climate change has led to not only the decrease in precipitation, but also the increase of precipitation intensity, which are not conducive to the transformation from precipitation to water resources [38]. Meanwhile, water demand variation mainly depends on the change of agricultural water demand. Thus, the socioeconomic water demand variation is not taken into consideration in this paper, since the socioeconomic water demand is more complicated and uncertain. On the one hand, the socioeconomic development, the improvement in living standards and urbanization can increase the water demand. On the other hand, the development of water saving technology and enhancement of water use efficiency will decrease the water demand contrarily. Therefore, water demand in 2020, which is very unpredictable, was assumed to equal water demand in 2010. Then, with the decrease of water resources $\left(-5.73 \times 10^{7} \mathrm{~m}^{3}\right.$ per year), the water resources can be calculated in 2020 on the basis of data in 2010. Furthermore, the DMAI were obtained from the optimal water allocation model (Figure 9). The result shows that the reduction of water resources results in the DMAI decrease for all if the units, especially the DMAI of Units 6-13 in the downstream plain areas, and this points out that the plain areas is more sensitive to drought.

\subsubsection{Interbasin Water Transfer Project Impact on the Drought Mitigation Ability Index (DMAI)}

To combat against water shortage in north China, China launched the South-to-North Water Transfer Project (SNWTP) in 2002, which planned three routes (eastern, middle and western) to transfer 45 billion $\mathrm{m}^{3}$ of water per year to north China. Among them, the middle route of SNWTP was mainly designed to solve the water shortage and drought issues in the North China Plain, especially in Beijing and Tianjin. After more than 12 years of engineering construction, the first stage of the middle route, with the target to transfer 9.5 billion $\mathrm{m}^{3}$ of water per normal year, was initially completed on 
12 December 2014. Additionally, the first stage of the middle route of SNWTP was planned to divert about one billion $\mathrm{m}^{3}$ of water per normal year into the Daqinghe watershed, mostly depending on Wangkuai reservoir and Xidayang reservoir. Hence, it will result in a significant DMAI increase of the Daqinghe watershed in 2020. Therefore, with the effectiveness of the middle route of SNWTP, the DMAI was obtained by the water allocation model in 2020 (Figure 9). The result shows that the DMAI increases overall for the watershed, especially in the units with low DMAI in plain areas. The reason is that the rising water level in reservoirs cannot only improve the water supply of Units 7 and 8 directly, but also can be beneficial to downstream units' water supply indirectly by optimal water allocation.
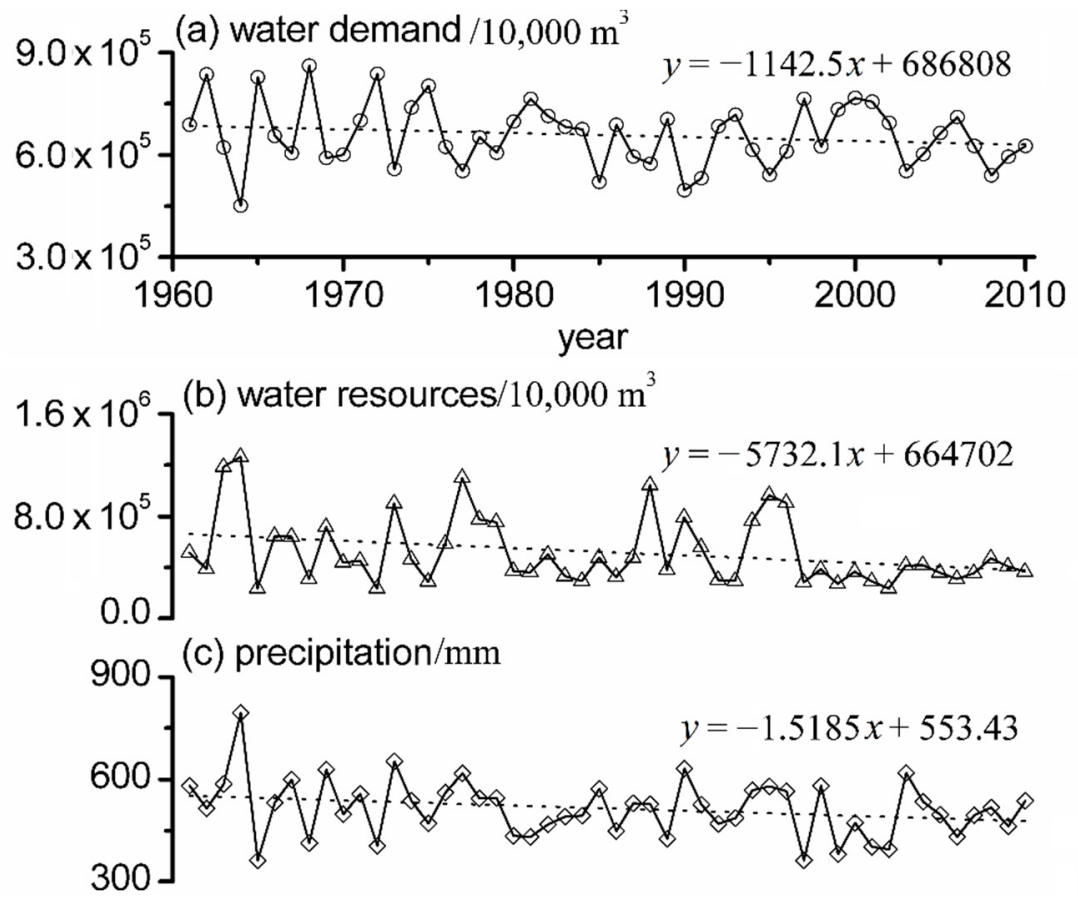

Figure 8. Trends of annual (a) water demand and (b) and resources annual (c) precipitation within the Daqinghe watershed.

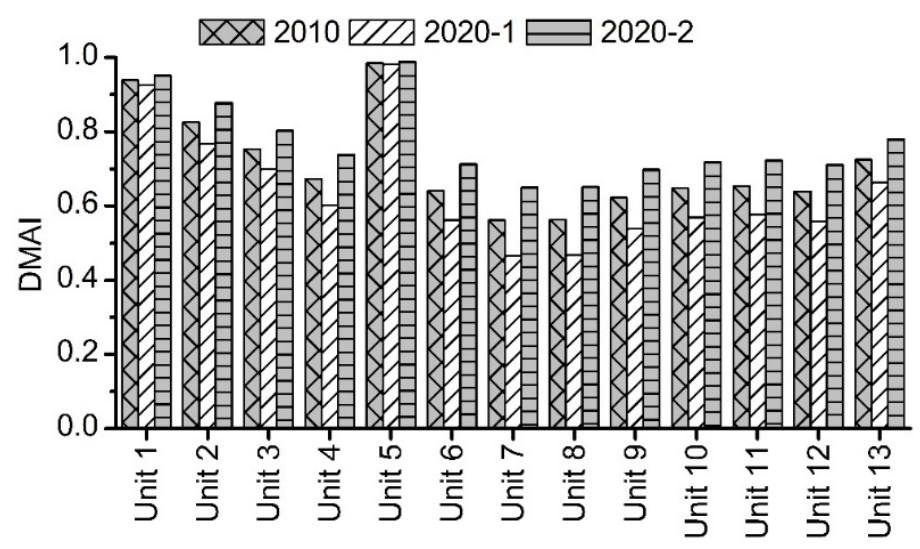

Figure 9. DMAI in different scenarios: 2010 represents the DMAI in 2010; 2020-1 represents the DMAI with the impact of the water resource decrease in 2020;2020-2 represents the DMAI with the function of South-to-North Water Transfer Project (SNWTP) on the basis of the water resource decrease in 2020. 


\section{Conclusions}

Droughts, as an imbalance of the performance of water resource systems, have been a worldwide obstacle to the development of socioeconomic systems, especially in developing countries. Additionally, it is inevitable and urgent to quantify the drought mitigation ability for drought risk management. Therefore, the DMAI was constructed to represent the regional ability of drought mitigation. In addition, the DMAI was applied in the Daqinghe watershed. First, the results show that the DMAI can represent the temporal-spatial characteristics of drought mitigation in the Daqinghe watershed by the comparison with the agricultural affected areas and the distribution of groundwater overexploitation. Second, the DMAI of the Daqinghe watershed is significantly decreased in the last 50 years, and the groundwater plays a prominent role in the response to drought mitigation, particularly in drought years. Additionally, the plain areas are more sensitive to drought impact than mountain areas, and the agricultural drought will still be a challenge to the Daqinghe watershed. Furthermore, the DMAI in 2020 was calculated in the scenarios of a water resource decrease and SNWTP. The result indicates that without SNWTP, there will be a high drought risk in 2020 due to the water resource decrease. Meanwhile, although the water from SNWTP can slightly improve the DMAI of the Daqinghe watershed, the drought risk continues to be serious. Generally speaking, although there is still some uncertainty in DMAI validation and application due to the limitation of data material and the complexity of drought mitigation and the water supply system, the DMAI is an effective index to quantify the ability of drought mitigation, which is indispensable for drought risk management.

\section{Acknowledgments}

This work was supported by the General Program of the National Natural Science Foundation of China under Grant 51279207 and Grant 51409266; and the National Science and Technology Support Program Project under Grant 2012BAC19B03 and Grant 2013BAC10B01.

\section{Author Contributions}

Denghua Yan had the original idea and supervised the research. Jianhua Wang and Baisha Weng performed the data collection. Shaohua Liu performed the statistical analysis and prepared the manuscript. Gang Wang performed partial statistical analysis, and Meijian Yang reviewed the manuscript.

\section{Conflicts of Interest}

The authors declare no conflict of interest.

\section{References}

1. Heim, R.R., Jr. A review of twentieth-century drought indices used in the United States. Bull. Am. Meteorol. Soc. 2002, 83, 1149-1165.

2. Mishra, A.K.; Singh, V.P. Drought modelling-A review. J. Hydrol. 2011, 403, 157-175.

3. Shiau, J.T.; Hsiao, Y.Y. Water-deficit-based drought risk assessments in Taiwan. Nat. Hazards 2012, 64, 237-257. 
4. Yan, D.; Weng, B.; Wang, G.; Wang, H.; Yin, J.; Bao, S. Theoretical framework of generalized watershed drought risk evaluation and adaptive strategy based on water resources system. Nat. Hazards 2014, 73, 259-276.

5. Hughes, D.A.; Kingston, D.G.; Todd, M.C. Uncertainty in water resources availability in the Okavango River basin as a result of climate change. Hydrol. Earth Syst. Sci. 2011, 15, 931-941.

6. Alcamo, J.; Flörke, M.; Märker, M. Future long-term changes in global water resources driven by socio-economic and climatic changes. Hydrol. Sci. J. 2007, 52, 247-275.

7. Mishra, A.K.; Singh, V.P. A review of drought concepts. J. Hydrol. 2010, 391, 202-216.

8. Flörke, M.; Kynast, E.; Bärlund, I.; Eisner, S.; Wimmer, F.; Alcamo, J. Domestic and industrial water uses of the past 60 years as a mirror of socio-economic development: A global simulation study. Glob. Environ. Change 2013, 23, 144-156.

9. Liu, J.; Savenije, H.H. Food consumption patterns and their effect on water requirement in China. Hydrol. Earth Syst. Sci. Discuss. 2008, 12, 887-898.

10. Pereira, L.S.; Cordery, I.; Iacovides, I. Coping with Water Scarcity: Addressing the Challenges; Springer Science and Business Media: Berlin, Germany, 2009.

11. Steduto, P.; Faurès, J.M.; Hoogeveen, J.; Winpenny, J.; Burke, J. Coping with Water Scarcity: An Action Framework for Agriculture and Food Security; Food and Agriculture Organization of the United Nations: Rome, Italy, 2012.

12. Chang, F.J.; Wang, K.W. A systematical water allocation scheme for drought mitigation. J. Hydrol. 2013, 507,124-133.

13. Wilhite, D.A.; Svoboda, M.D.; Hayes, M.J. Monitoring drought in the United States: Status and trends. In Monitoring and Predicting Agricultural Drought: A global Study; Oxford University Press: New York, NY, USA, 2005; pp. 121-131.

14. Luo, L.; Wood, E.F. Monitoring and predicting the 2007 US drought. Geophys. Res. Lett. 2007, 34, doi:10.1029/2007GL031673.

15. Tsakiris, G.; Pangalou, D.; Vangelis, H. Regional drought assessment based on the Reconnaissance Drought Index (RDI). Water Resour. Manag. 2007, 21, 821-833.

16. Weng, B.S.; Yan, D.H.; Wang, H.; Qin, T.L.; Yin, J. Generalized drought assessment in Dongliao river basin based on water resources system. Nat. Hazards Earth Syst. Sci. Discuss. 2014, 2, 6703-6746.

17. McKee, T.B.; Doesken, N.J.; Kleist, J. The relationship of drought frequency and duration to time scales. In Proceedings of the 8th Conference on Applied Climatology, Anaheim, CA, USA, 17-22 Januray 1993.

18. McKee, T.B.; Doesken, N.J.; Kleist, J. Drought monitoring with multiple time scales. In Ninth Conference on Applied Climatology; American Meteorological Society: Boston, MA, USA, 1995.

19. Palmer, W.C. Meteorological Drought; US Department of Commerce, Weather Bureau: Washington, DC, USA, 1965.

20. Shafer, B.A.; Dezman, L.E. Development of a surface water supply index (SWSI) to assess the severity of drought conditions in snowpack runoff areas. In Proceedings of the Western Snow Conference, Reno, NV, USA, 19-23 April 1982.

21. Hollinger, S.E.; Isard, S.A.; Welford, M.R. A new soil moisture drought index for predicting crop yields. In Proceedings of the 8th Conference on Applied Climatology, San Francisco, CA, USA, 17-22 January 1993. 
22. Wilhite, D.A.; Svoboda, M.D.; Hayes, M.J. Understanding the complex impacts of drought: A key to enhancing drought mitigation and preparedness. Water Resour. Manag. 2007, 21, 763-774.

23. Yevjevich, V.; Hall, J.D.; Salas, W. Drought Research Needs; Water Resources Publications: Littleton, CO, USA, 1978.

24. Huang, W.C.; Chou, C.C. Drought early warning system in reservoir operation: Theory and practice. Water Resour. Res. 2005, 41, doi:10.1029/2004WR003830.

25. Sechi, G.M.; Sulis, A. Drought mitigation using operative indicators in complex water systems. Phys. Chem. Earth 2010, 35, 195-203.

26. Rossi, G.; Castiglione, L.; Bonaccorso, B. Guidelines for planning and implementing drought mitigation measures. In Methods and Tools for Drought Analysis and Management; Springer Netherlands: Dordrecht, The Netherlands, 2007; pp. 325-347.

27. Vicente-Serrano, S.M.; Beguería, S.; Gimeno, L.; Eklundh, L.; Giuliani, G.; Weston, D.; Pegram, G.G. Challenges for drought mitigation in Africa: The potential use of geospatial data and drought information systems. Appl. Geogr. 2012, 34, 471-486.

28. Vogt, J.V.; Somma, F. Drought and Drought Mitigation in Europe; Kluwer Academic Publishers: Norwell, MA, USA, 2013.

29. Shih, J.S.; ReVelle, C. Water-supply operations during drought: Continuous hedging rule. J. Water Resour. Plan. Manag. 1994, 120, 613-629.

30. Wilhite, D.A. Drought and Water Crises: Science, Technology, and Management Issues; CRC Press: Boca Raton, FL, USA, 2014.

31. China Meteorolgical Data Sharing System. Available online: http://cdc.nmic.cn/home.do (accessed on 7 April 2015).

32. Smith, M. CROPWAT: A Computer Program for Irrigation Planning and Management; Food and Agriculture Organization of the U.N. Rome: Rome, Italy, 1992.

33. Döll, P.; Siebert, S. Global modelling of irrigation water requirements. Water Resour. Res. 2002, 38, doi:10.1029/2001WR000355.

34. Qin, Y.; Yang, D.; Lei, H.; Xu, K.; Xu, X. Comparative analysis of drought based on precipitation and soil moisture indices in Haihe basin of North China during the period of 1960-2010. J. Hydrol. 2014, in press.

35. Sun, K.K.; Chen, J.; Jin, J.; Li, J.Q.; Xu, J.J.; Fei, Z.Y. Calculation method of agricultural drought loss risk curve under the actual drought resistance ability condition in Southern China. J. Hydraul. Eng. 2014, 7, 809-815. (In Chinese)

36. Mishra, A.K.; Singh, V.P.; Desai, V.R. Drought characterization: A probabilistic approach. Stoch. Environ. Res. Risk Assess. 2009, 23, 41-55.

37. Wang, Z.G.; Luo, Y.Z.; Zhang, M.H.; Xia, J. Quantitative evaluation of sustainable development and eco-environmental carrying capacity in water-deficient regions: A case study in the Haihe River Basin, China. J. Integr. Agric. 2014, 13, 195-206.

38. Zhang, X.; Cong, Z. Trends of precipitation intensity and frequency in hydrological regions of China from 1956 to 2005. Glob. Planet. Change 2014, 117, 40-51.

(C) 2015 by the authors; licensee MDPI, Basel, Switzerland. This article is an open access article distributed under the terms and conditions of the Creative Commons Attribution license (http://creativecommons.org/licenses/by/4.0/). 